\title{
Estimation of Disease Activity in Rheumatoid Arthritis: A Correlation Study between Clinical, Inflammatory Markers and Power Doppler Ultrasonography
}

\author{
Tuhin S Sarkar ${ }^{1}$, Kripasindhu Gantait ${ }^{2}$
}

\begin{abstract}
Objective: To correlate between clinical, inflammatory markers and power Doppler (PD) ultrasonography (USG) to assess the disease activity in rheumatoid arthritis (RA) patients.

Methods: Sixty consecutive patients with RA were included. Demographic and clinical data, C-reactive protein (CRP) level, and erythrocyte sedimentation rate (ESR) were recorded. All patients underwent an USG PD by an experienced ultrasonologist. USG joint effusion, synovitis, and PD signal were graded from 1 to 3 in a small joint of both hands (metacarpophalangeal, proximal interphalangeal, and wrist). Joint count and joint index for effusion, synovitis, and PD signal were recorded for a total of 22 joints.

Result: Among 60 patients, 41 were female and 19 were male. The correlation coefficient between ESR with tender joint, swollen joint, USG synovitis, and USG hyperemia was $0.13,0.13,0.58$, and 0.33 , respectively. The correlation coefficient between CRP with tender joint, swollen joint, USG synovitis, and USG hyperemia was $0.46,0.07,0.36$, and 0.27 , respectively.

Conclusion: USG PD is an important tool along with clinical assessment and inflammatory marker to assess the disease activity in RA patients. Keywords: CRP, ESR, Rheumatoid arthritis, USG Power Doppler.

Bengal Physician Journal (2020): 10.5005/jp-journals-10070-7038
\end{abstract}

\section{INTRODUCTION}

Rheumatoid arthritis (RA) is the most common form of chronic inflammatory arthritis in a symmetric distribution. The usual feature of an established RA is persistent inflammatory synovitis that routinely involves the peripheral joint. ${ }^{1}$ Traditionally, the disease activity has been estimated by clinical, biochemical, and radiological measures..$^{2-4}$ Musculoskeletal imaging in rheumatology has greatly been improved with high-frequency ultrasonography (USG). A number of studies have shown the relation between power Doppler (PD) quantification and biochemical measures of disease activity in RA. A link between Doppler activity in the synovium and high values of both erythrocyte sedimentation rate (ESR) and C-reactive protein (CRP) has been established. . $^{5-8}$

Similarly, a relation between Doppler activity and tender and the swollen joint count has been demonstrated. ${ }^{9}$

\section{Methods}

Participants ( $n=60$ ) diagnosed as RA based on 2010 ACR/EULAR criteria, attending the outpatient rheumatology clinic, were included. Participants with traumatic, septic, or microcrystalline arthritis and previous joint surgery within the past 12 months before the study were excluded. The following data were recorded for each patients: age, sex, disease duration, tender joint count, swollen joint count, rheumatoid factor, CRP level, and ESR. Joint count was only recorded in joints of hands (metacarpophalangeal, proximal interphalangeal, and wrist) (total 22 joint).

\section{Results}

Among the 60 patients, 41 were female and 19 were male. The mean age of the study population was $41.76 \pm 12.05$ (mean \pm S.D.)
${ }^{1}$ RG Kar Medical College, Kolkata, West Bengal, India

${ }^{2}$ Midnapore Medical College, Midnapore, West Bengal, India

Corresponding Author: Kripasindhu Gantait, Midnapore Medical College, Midnapore, West Bengal, India, Phone:+91 9434243054, e-mail:drkripa2000@gmail.com

How to cite this article: Sarkar TS, Gantait K. Estimation of Disease Activity in Rheumatoid Arthritis: A Correlation Study between Clinical, Inflammatory Markers and Power Doppler Ultrasonography. Bengal Physician Journal 2020;7(3):55-56.

Source of support: Nil

Conflict of interest: None

where the minimum was 20 years and the maximum was 69 years. The mean (mean \pm S.D.) of ESR and CRP was $42.26 \pm 20.60$ and $6.01 \pm 5.75$, respectively. The mean (mean \pm S.D.) joint count for tender joint, swollen joint, USG PD-detected joint synovitis, and USG PD-detected joint hyperemia was $5.1 \pm 4.8,1.2 \pm 2.7,5.3 \pm 3.7$, and $1.3 \pm 1.7$, respectively (Table 1 ).

\section{Discussion}

Naredo et al. done a similar type of study. They selected 90 consecutive patients with a mean (S.D.) age of 58.1 (14.3), mean tender joint count of 14 (16.1), mean swollen joint count of 10.9 (7.8), mean ESR of 28.4 (19.4), and mean CRP of 15 (19). ${ }^{7}$

Ellegaard et al. done a similar type of study among 109 patients (women, 78 and men, 31) with a median age of 59 years (range, 26-84 years). The median number of tender and swollen joints was 9 (range, 0-28) and 7 (range, 0-26), respectively. The median CRP was 13 (range, 1-168), and median ESR mg/L was 24.5 (range, $2-115) .^{10}$

\footnotetext{
(c) The Author(s). 2020 Open Access This article is distributed under the terms of the Creative Commons Attribution 4.0 International License (https:// creativecommons.org/licenses/by-nc/4.0/), which permits unrestricted use, distribution, and non-commercial reproduction in any medium, provided you give appropriate credit to the original author(s) and the source, provide a link to the Creative Commons license, and indicate if changes were made. The Creative Commons Public Domain Dedication waiver (http://creativecommons.org/publicdomain/zero/1.0/) applies to the data made available in this article, unless otherwise stated.
} 
Table 1: Correlation of ESR and CRP with clinical (tender and swollen joint) and USG PD (synovitis and hyperemia)

\begin{tabular}{lllll}
\hline & $\begin{array}{l}\text { Tender } \\
\text { joint }\end{array}$ & $\begin{array}{l}\text { Swollen } \\
\text { joint }\end{array}$ & $\begin{array}{l}\text { USG PD-detected } \\
\text { joint synovitis }\end{array}$ & $\begin{array}{l}\text { USG PD-detected } \\
\text { joint hyperemia }\end{array}$ \\
\hline ESR & 0.13 & 0.13 & 0.58 & 0.33 \\
CRP & 0.46 & 0.07 & 0.36 & 0.27 \\
\hline
\end{tabular}

In our study among the 60 patients, 41 were female and 19 were male. The mean (S.D) age of the study population was 41.76 (12.05) (range, 20-69). The mean (S.D.) of ESR and CRP was 42.26 (20.60) and 6.01 (5.75), respectively. The mean (mean \pm S.D.) joint count for tender joint, swollen joint, USG PD-detected joint synovitis, and USG PD-detected joint hyperemia was 5.1 (4.8), 1.2 (2.7), 5.3 (3.7), and $1.3(1.7)$, respectively.

In Naredo et al. study, the correlation coefficient between ESR with tender joint, swollen joint, USG synovitis, and USG hyperemia was $0.12,0.41,0.50$, and 0.45 , respectively. The correlation coefficient between CRP with tender joint, swollen joint, USG synovitis, and USG hyperemia was 0.08, 0.51, 0.63, and 0.62 , respectively. ${ }^{7}$

In Ellegaard et al. study, the correlation coefficient between USG PD with a tender joint count, swollen joint count, ESR, and CRP was $0.07,0.35,0.5$, and 0.5 , respectively. It shows a significant correlation between ESR and USG PD, CRP and PD, and swollen joint and PD study. ${ }^{10}$

In our study, the correlation coefficient between ESR with tender joint, swollen joint, USG synovitis, and USG hyperemia was $0.13,0.13,0.58$, and 0.33 , respectively. The correlation coefficient between CRP with tender joint, swollen joint, USG synovitis, and USG hyperemia was $0.46,0.07,0.36$, and 0.27 , respectively.

Since our results resemble those that are obtained in other studies, ${ }^{6,11,12}$ they are credible.

\section{Conclusion}

USG PD is an important tool along with clinical assessment and inflammatory marker to assess the disease activity in RA patients. Joint synovitis is detected more than joint hyperemia in USG PD.

\section{References}

1. Harrison's principle of internal medicine. 19th ed. McGraw-Hill Education/Medical; 2017. p. 2083.

2. Malaviya AN, Kapoor SK, Singh RR, et al. Rheumatol Int 1993;13(4); 131-134. DOI: 10.1007/BF00301258.

3. Van der Heijde DMFM, van't Hof MA, van Riel PLCM, et al. Development of a disease activity score based on judgment in clinical practice by rheumatologists. J Rheumatol 1993;20(3):579-581. PMID: 8478878

4. Felson DT, Anderson JJ, Boers M, et al. The American College of Rheumatology preliminary core set of disease activity measures for rheumatoid arthritis clinical trials. Arthritis Rheum 1993;36(6): 729-740. DOI: 10.1002/art.1780360601.

5. Terslev L, Torp-Pedersen S, Qvistgaard E, et al. Estimation of inflammation by Doppler ultrasound: quantitative changes after intra-articular treatment in rheumatoid arthritis, Ann Rheum Dis 2003;62(11):1049-1053. DOI: 10.1136/ard.62.11.1049.

6. Naredo E, Collado P, Cruz A, et al. Longitudinal power Doppler ultrasonographic assessment of joint inflammatory activity in early rheumatoid arthritis: predictive value in disease activity and radiologic progression. Arthritis Rheum 2007;57(1):116-124. DOI: 10.1002/art.22461.

7. Naredo E, Bonilla G, Gamero F, et al. Assessment of inflammatory activity in rheumatoid arthritis: a comparative study of clinical evaluation with grey scale and power Doppler ultrasonography. Ann Rheum Dis 2005;64(3):375-381. DOI: 10.1136/ard.2004.023929.

8. Filippucci E, lagnocco A, Salaffi F, et al. Power Doppler sonography monitoring of synovial perfusion at wrist joint in rheumatoid patients treated with adalimumab. Ann Rheum Dis 2006;65(11):1433-1437. DOI: 10.1136/ard.2005.044628.

9. Hau M, Kneitz C, Tony HP, et al. High resolution ultrasound detects a decrease in pannus vascularisation of small finger joints in patients with rheumatoid arthritis receiving treatment with soluble tumour necrosis factor alpha receptor (etanercept). Ann Rheum Dis 2002;61(1):55-58. DOI: 10.1136/ard.61.1.55.

10. Ellegaard K, Torp-Pedersen S, Terslev L, et al. Ultrasound colour Doppler measurements in a single joint as measure of disease activity in patients with rheumatoid arthritis-assessment of concurrent validity. Rheumatology 2009;48(3):254-257. DOI: 10.1093/rheumatology/ken459.

11. Naredo E, Gamero F, Bonilla G, et al. Ultrasonographic assessment of inflammatory activity in rheumatoid arthritis: comparison of extended versus reduced joint evaluation. Clin Exp Rheumatol 2005;23(6):881-884. PMID: 16396709

12. Hameed B, Pilcher J, Heron C, et al. The relation between composite ultrasound measures and the DAS28 score, its components and acute phase markers in adult RA. Rheumatology 2008;47(4):476-480. DOI: 10.1093/rheumatology/kem383. 